\title{
PSYCOLOGICAL AND SOCIAL DETERMINANTS OF QUALITY OF LIFE AMONG THE ELDERLY WITH DIABETES MELLITUS
}

\author{
Hari-Peni Julianti, Aras-Utami, Dea Amarilisa Adespin, \\ Diah Rahayu Wulandari, Trilaksana Nugroho, Ani Margawati
}

Public Health Program-Preventive Medicine, Faculty of Medicine, Universitas Diponegoro

\begin{abstract}
Background: Diabetes Mellitus (DM) is a non infectious disease with an increasing incidence in Indonesia. Financial, social and psychological handicaps are integral to all chronic diseases, but diabetes differs in two important respects. Firstly, although it affects virtually every aspect of everyday life to a greater or lesser degree, the patient is encouraged to lead a "normal life" without any of the concessions usually made to a person with chronic illness. Secondly, although the treatment is demanding and often complex, the patient is expected to bear much of the responsibility for making decisions which may effect his health, both in the short and long term. This study aimed to investigate the psycological and social determinants of quality of life among the elderly with diabetes mellitus.
\end{abstract}

Subjects and Method: A cross sectional study was conducted in the area of the practice of Interprofessional Education (IPE) Faculty of Medicine, Universitas Diponegoro, Rowosari Health Center, Semarang, Central Java. A sample of 67 diabetic patients was selected for this study at random. The independent variables includeed the social determinants, which consisted of sex, education level, economic status, and health insurance status; the family function; and the family resources. The family function was measured by family APGAR. The family resources were measured by family SCREEM. The dependent variable was quality of life consisting of cognitive function, depression, and functional ability. These various aspects of quality of life were measured by Mini Mental Examination Scale, Geriatric Depression Scale, Barthel Index, and Short Form-36. The data were analyzed using chi-square with prevalence ratio (PR) as the measure of association.

Results: Family function ( $P R=5.15 ; 95 \% \mathrm{CI}=1.67$ to $15.6 ; \mathrm{p}=0.003)$, absence of depression $(\mathrm{PR}=5.31 ; 95 \% \mathrm{CI}=1.81$ to $15.56 ; \mathrm{p}=0.002)$, cognitive function $(\mathrm{PR}=15.33$; $95 \% \mathrm{CI}=3.19$ to $73.62 ; \mathrm{p} \leq 0.010)$, functional ability $(\mathrm{PR}=7.33 ; 95 \% \mathrm{CI}=1.96$ to 28.27 ; $\mathrm{p}=0.002)$, were positively associated with quality of life. The associations between sex $(\mathrm{PR}=0.84 ; 95 \% \mathrm{CI}=0.311$ to $2.26 ; \mathrm{p}=0.729)$, education level $(\mathrm{PR}=4.11 ; 95 \% \mathrm{CI}=0.93$ to $18.22 ; \mathrm{p}=0.050)$, economic status $(\mathrm{PR}=1.88 ; 95 \% \mathrm{CI}=0.65$ to $5.39 ; \mathrm{p}=0.239)$, health insurance status $(P R=1.25 ; 95 \% \mathrm{CI}=0.35$ to $4.46 ; \mathrm{p}=0.731)$, and family resources $(\mathrm{PR}=2.00 ; 95 \% \mathrm{CI}=0.73$ to $5.47 ; \mathrm{p}=0.175)$, and quality of life were statistically non-significant.

Conclusion: Family function, absence of depression, cognitive function, functional ability are associated with quality of life in the elderly with diabetes mellitus.

Keywords: elderly, diabetes mellitus, quality of life, determinant

\section{Correspondence:}

Hari-Peni Julianti. Public Health Program-Preventive Medicine. Faculty of Medicine Diponegoro University, Semarang, Central Java. Email: hari_peni@yahoo.com.

Mobile: 081808472018.

The $5^{\text {th }}$ International Conference on Public Health Best Western Premier Hotel, Solo, Indonesia, February 13-14, 2019 | 141 https://doi.org/10.26911/theicph.2019.01.48 